\title{
Prescribing pattern of antidiabetic drugs in tertiary care hospital
}

\author{
Pothuru Anil Kumar ${ }^{1}$, Keelu Raj Kumar ${ }^{2 *}$
}

\author{
${ }^{1}$ Department of Pharmacology, Viswabharathi Medical College, Kurnool, Andhra Pradesh, India \\ ${ }^{2}$ Department of Pharmacology, Shanthiram Medical College, Kurnool, Andhra Pradesh, India
}

Received: 07 January 2021

Revised: 05 February 2021

Accepted: 08 February 2021

\section{*Correspondence:}

Dr. Keelu Raj Kumar,

Email: rajkumarkeelu@gmail.com

Copyright: (C) the author(s), publisher and licensee Medip Academy. This is an open-access article distributed under the terms of the Creative Commons Attribution Non-Commercial License, which permits unrestricted non-commercial use, distribution, and reproduction in any medium, provided the original work is properly cited.

\begin{abstract}
Background: The aim of the current study was to investigate the prescribing pattern of anti-diabetic drugs in diabetic patients attending tertiary care teaching hospital in Kurnool.

Methods: A prospective, cross-sectional, observational survey was carried out in 100 patients of diabetes mellitus attending diabetes outpatient/medicine outpatient departments, to assess their prescribing pattern of anti-diabetic drugs.

Results: Average number of anti-diabetic drugs per prescription was 1.4. Metformin (biguanide) was the commonest prescribed individual drug among oral hypoglycemic agents. Fixed dose combination of biguanide and sulfonylurea was prescribed commonly. Monotherapy dominated over polytherapy and there was a higher percentage of use of insulin in type 2 diabetics.

Conclusions: OHAs still dominate the prescribing pattern, but there was a shifting trend toward the use of insulin preparations in the management of type 2 diabetes mellitus. Intensification of current drug treatment as well as planning multiple drug interventions with lifestyle modification is necessary.
\end{abstract}

Keywords: Anti-diabetic drugs, Glycemic control, Insulin, Oral hypoglycemic agents, Prescribing pattern

\section{INTRODUCTION}

Diabetes mellitus is a heterogeneous group of diseases characterized by chronic elevation of glucose in the blood. It arises because the body is unable to produce enough insulin for its own needs, either because of impaired insulin secretion, impaired insulin action, or both. Diabetes affects kidneys and cause renal failure, visual loss and a range of other types of tissue damage. Diabetes also predisposes to arterial disease, not least because it is often accompanied by hypertension, lipid disorders and obesity. Many cases of diabetes and almost all of its unwanted long-term consequences are potentially avoidable, but this will require intervention at a societal as well as at a medical level.
Diabetes mellitus is a pandemic disease that has struck each and every corner of the world. India currently has 62.4 million people with diabetes. This is set to increase to over 100 million by 2030 . The prevalence of diabetes among adults has reached approximately $20 \%$ in urban and approximately $10 \%$ in rural populations in India. Various classes of anti-diabetic drugs including insulin and oral hypoglycemic agents (OHA) are currently used in the treatment of diabetes, which acts by different mechanisms to reduce the blood glucose levels to maintain optimal glycemic control. ${ }^{1,2}$

More than $50 \%$ of people with diabetes have poor glycemic control, uncontrolled hypertension and dyslipidemia, and a large percentage have diabetic 
vascular complications. ${ }^{3,4}$ Therefore, current study was carried out to find the current prescribing pattern of antidiabetic drugs and efficacy of these drugs in maintaining adequate glycemic control in diabetic patients attending a tertiary care teaching hospital in Kurnool.

\section{METHODS}

Current study was a cross-sectional, prospective, observational study carried out in diabetology and medicine department of a tertiary care hospital in Kurnool. The sample size for this study was 100 patients (95\% confidence interval, $\pm 10 \%$ ) in accordance with world health organization (WHO) manual to assess drug use in individual facilities..$^{5}$ It was a pilot study with duration of 2 months (10 August 2019 to 10 October, 2019 ) in which 100 patients of diabetes who are receiving anti-diabetic therapy for more than one year was randomly selected.

\section{Inclusion criteria}

Inclusion criteria for current study were; all type 2 diabetes mellitus patients of both sexes irrespective of age and on treatment with oral hypoglycemic agents and insulin therapy.

\section{Exclusion criteria}

Exclusion criteria for current study were; pregnant/lactating woman, patients of type 1 diabetes mellitus (DM), pediatric cases and patients with gestational diabetes.

\section{Statistical analysis}

Data was entered using Microsoft excel quantitative variables as mean \pm SD. Prescribing drug products were expressed in percentages.

\section{RESULTS}

One hundred $(n=100)$ patients of type 2 diabetes were analyzed and 50 anti-diabetic drug products were prescribed. Male were $52 \%(N=52)$, female were $48 \%$ $(N=48)$ (Figure 1).

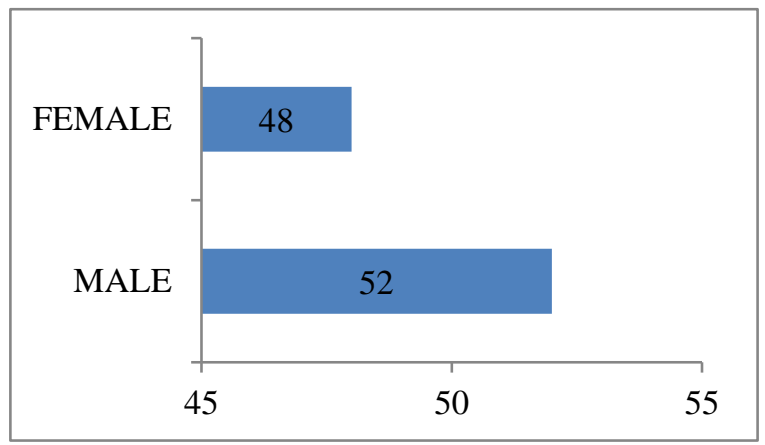

Figure 1: Number of males and females.

\section{Prescribing pattern}

During the study, the number of anti-diabetic drug products per prescription varied from one to four and the average number of anti-diabetic drugs per prescription was 1.4. Out of total 140 prescribed anti-diabetic drug products, $74(52.86 \%)$ were OHA and $66(47.14 \%)$ were insulin (Figure 2).

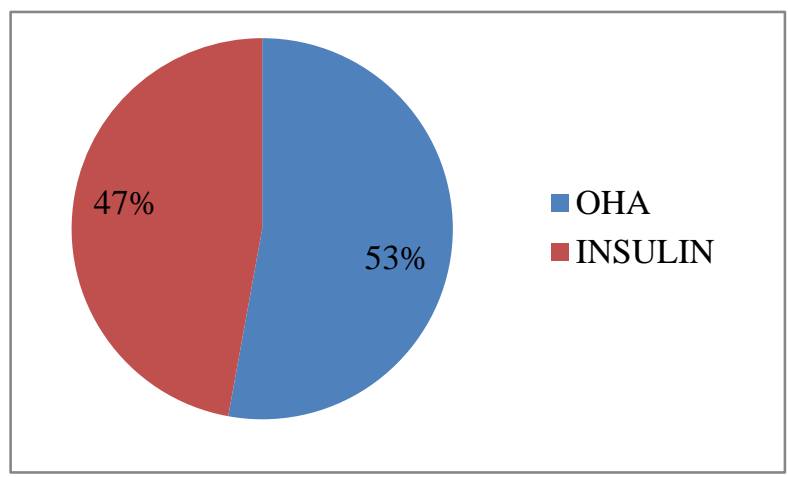

Figure 2: Percentage of OHA and insulin prescribed.

Thus OHA's were the most common class of antidiabetic drugs prescribed in this study. Biguanides (35\%) were the most commonly prescribed class followed by fixed dose combination (FDC)-sulfonylureas+biguanides (29\%) among the different classes of OHA (Figure 3). Metformin (biguanide) was the most common individual OHA to be prescribed followed by FDC of glimepiride plus metformin 29\%. Other classes of OHA prescribed were thiazolidinediones $9.5 \%$ and dipeptidyl peptidase 4 inhibitors (DPP 4 inhibitors) $4.8 \%$ and FDCbiguanides+DPP-4 inhibitors are $2.4 \%$.

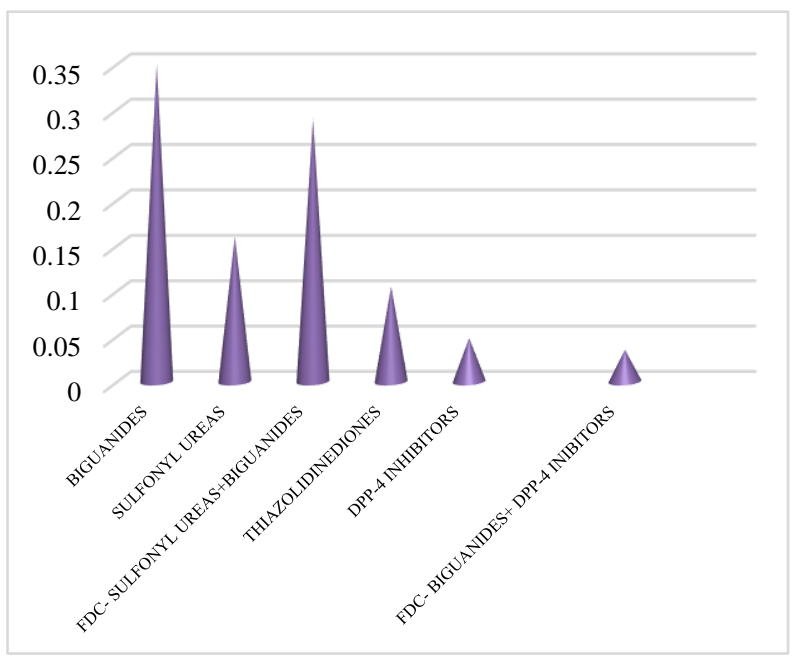

Figure 3: Prescribing frequency of different class of OHAs.

Insulin preparations accounted for $47 \%$ of the total antidiabetic drugs in which short acting insulin $47 \%$ followed by insulin mixture preparations $33 \%$, others are ultra short acting and intermediate insulin are $10 \%$ each. 


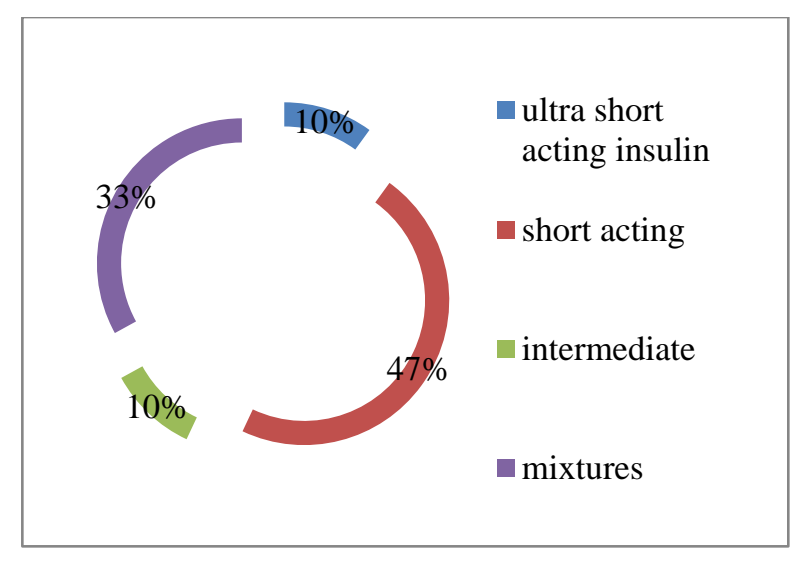

Figure 4: Prescribing frequency of different insulin preparations.

\section{DISCUSSION}

In this study, an attempt has been made to describe the current prescribing pattern and trend of anti-diabetic drug therapy in diabetic patients in a tertiary care hospital in Kurnool.

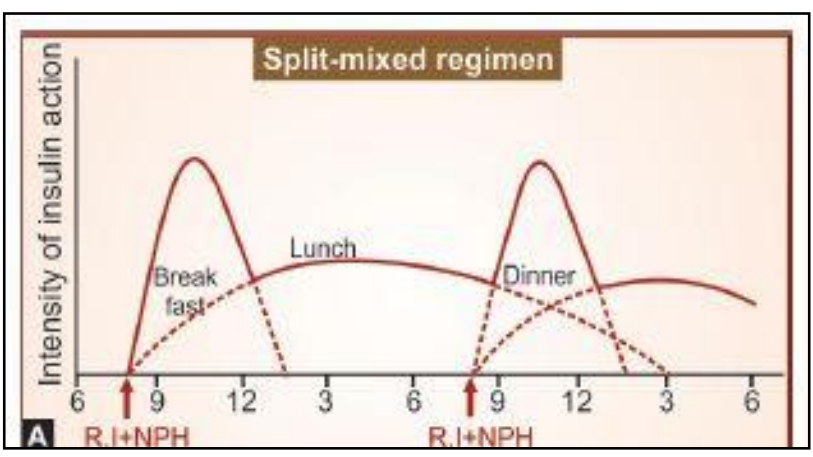

Figure 5: Insulin action obtained with regular insulin and NPH.

In current study, out of 100 patients who were treated with anti-diabetic drugs all of them were type 2 diabetic patients (noninsulin dependent diabetes mellitus) that reflect the increasing prevalence of type 2 diabetes mellitus in our region. The average number of antidiabetic drugs per prescription in this study was 1.4. Our study showed restraint on polypharmacy. In current study, male preponderance is seen compare to females similar to a finding in a study done by Mahamood et al. ${ }^{6}$ OHAs were commonly prescribed drugs accounting for $53 \%$ of the total prescribed anti-diabetic products. Biguanides (35\%) were the most commonly prescribed class followed by FDC-sulfonylureas+biguanides (29\%), similar to finding of et al. Biguanides are used in combination with other OHAs in order to achieve better glycemic control. ${ }^{8}$

Insulin preparations accounted for $47 \%$ of the total antidiabetic drugs and the most common preparation was short acting insulin preparation followed by mixtures (split-mixed regimen), the total daily dose of a 30:70 or
50:50 mixture of regular and NPH (neutral protamine hagedorn/isophane) insulin is usually split into two (splitmixed regimen) and injected subcutaneously before breakfast and before dinner (Figure 5). Insulin preparations can provide intensive, near physiologic delivery of insulin and can help patients achieve better glycemic control. ${ }^{9}$ This reflects a change in prescribing trend and shift toward insulin based therapy from the dominated class of OHA in type 2 diabetes treatment. Thus, lifestyle modification along with anti-diabetic drug treatment has the potential to improve glycemic control in patients with type 2 diabetes despite optimized antidiabetic drug treatment. ${ }^{10,11}$ In this study, all drugs were prescribed by brand name suggesting popularity of the brands among the physician and influence of pharmaceutical companies on the physician. It is advisable to prescribe by generic name for cost effective utilization.

\section{CONCLUSION}

Oral hypoglycemic agents still dominate the prescribing pattern, but there was a shifting trend toward the use of insulin preparations in the management of type 2 diabetes mellitus. In achieving optimal glycemic control, intensification of current drug treatment as well as planning multiple drug interventions with lifestyle modification is necessary to prevent diabetic complications.

\section{Funding: No funding sources Conflict of interest: None declared Ethical approval: Not required}

\section{REFERENCES}

1. Davis SN. Insulin, oral hypoglycemic agents, and pharmacology of the endocrine pancreas. In: Brunton LL, Lazo JS, Parker KL, eds. Goodman and Gilman`s, the pharmacological basis of therapeutics. 11th ed. USA: McGraw-Hill; 2006:1613-45.

2. Powers AC. Diabetes mellitus. In: Kasper DL, Braunwald E, Fauci AS, Hauser SL, Lango DL, Jameson JL, eds. Harrison`s principles of internal medicine. 16th ed. New York: McGraw-Hill; 2005: 2152-80.

3. Raheja BS, Kapur A, Bhoraskar A, Sathe SR, Jorgensen LN, Moorthi SR, et al. Diabetes care in India-current status. J Assoc Physicians India. 2001; 49:717-22.

4. Nagpal J, Bhartia A. Quality of diabetes care in the middle and high income group populace. Diabetes Care. 2006;29:2341-8.

5. How to investigate drug use in health facilities: selected drug use indicators, WHO. Available at: https://www.who.int/medicines/publications/how-toinvestigate_drug-use/en/. Accessed on 20 November 2020.

6. Orlando V, Guerriero F, Putignano D. Prescription patterns of antidiabetic treatment in the elderly. 
results from Southern Italy. Curr Diabetes Rev. 2015;12(2):100-6.

7. Agarwal AA, Jadhav PR, Deshmukh YA. Prescribing pattern and efficacy of anti-diabetic drugs in maintaining optimal glycemic levels in diabetic patients. J Basic Clin Pharm. 2014;5(3):7983.

8. Sultana G, Kapur P, Aqil M, Alam MS, Pillai KK. Drug utilization of oral hypoglycemic agents in a university teaching hospital in India. J Clin Pharm Ther. 2010;35:267-77.

9. Shah S, Das AK, Kumar A, Unnikrishnan AG, Kalra S, Baruah MP, Ganapathi B, Sahay RK. Baseline characteristics of the Indian cohort from the improve study: a multinational, observational study of biphasic insulin aspart 30 treatment for type 2 diabetes. Adv Ther. 2009;26(3):325-35.
10. UK prospective diabetes study (UKPDS) group. Effect of intensive blood-glucose control with metformin on complications in overweight patients with type 2 diabetes (UKPDS 34). Lancet. 1998;352 (9131):854-65.

11. UK prospective diabetes study (UKPDS) group. Intensive blood glucose control with sulphonylureas or insulin compared with conventional treatment and risk of complications in patients with type 2 diabetes (UKPDS 33). Lancet 1998;352:837-53.

Cite this article as: Kumar PA, Kumar KR. Prescribing pattern of antidiabetic drugs in tertiary care hospital. Int J Basic Clin Pharmacol 2021;10:251-4. 